\title{
INCREASE IN MATERNAL MORTALITY ASSOCIATED WITH CHANGE IN THE REPRODUCTIVE PATTERN IN SPAIN: 1996-2005.
}

\section{Miguel Ángel Luque Fernández ${ }^{a, *}$}

\author{
Aurora Bueno Cavanillas ${ }^{b}$ \\ Michèle Dramaix-Wilmet ${ }^{c}$ \\ Fernando Simón Soria ${ }^{d}$ \\ Juan de Mata Donado Campos ${ }^{\mathrm{e}}$ \\ Dionisio Herrera Guibert ${ }^{\dagger}$
}

\footnotetext{
${ }^{a}$ National Centre for Epidemiology (Centro Nacional de Epidemiología - CNE), Field Epidemiology Training Programme (FETP),

Carlos III Institute of Health,

C/Sinesio Delgado 6, Pabellón 12, 28029 Madrid, Spain.

${ }^{b}$ Faculty of Medicine: Department of Preventive Medicine and Public Health. University of Granada, Spain.

Avenidad de Madrid, 11. 18012. Granada, Spain.

${ }^{c}$ School of Public Health: Department of Biostatistics. Université Libre de Bruxelles (ULB), Route de Lennik 808, 1070 Brussels - Belgium.

d,e,f National Centre for Epidemiology (Centro Nacional de Epidemiología-CNE), Carlos III Institute of Health,

C/Sinesio Delgado 6, Pabellón 12, 28029 Madrid, Spain.
}

*Corresponding author. Tel.: +34 627968696.

E-mail address: $\underline{\text { fmiguelangel@isciii.es }}$ 


\begin{abstract}
Background:

In Europe different studies forecast an increase in maternal mortality for the next years, associated with advanced maternal age and delay in maternity. This study aims to analyse the age-related trend in the maternal mortality ratio among mothers in Spain for the decade, 1996-2005; and describe the causes of death and associated socio-demographic factors for the years with highest mortality.
\end{abstract}

\title{
Methods:
}

An ecological study on trends, for the age-related trend in the maternal mortality ratio; an indirect standardisation and poisson regression model was used. For the description of the causes of death, a cross-sectional study was used.

\section{Results:}

Prevalence of live births among mothers aged 35 years and over was 15\% higher in Spain than in Europe. The maternal mortality rate increased by $20 \%$ (Standardised Mortality Ratio of $1.2,95 \% \mathrm{Cl}=0.9-1.4$ ) in 2005 with respect to 1996. The age-related risk of maternal mortality was 3 times higher (relative risk of $2.90,95 \% \mathrm{Cl}$ [2.01-4.06]) among mothers aged 35 to 44 years versus those aged under 35 years. The highest mortality was detected during 2003-2004. The risk of maternal mortality was higher in foreign mothers.

\section{Conclusion:}

This study confirms that there was a change in the maternal mortality trend characterised by an increase in deaths, associated with advanced maternal age, as well as an increase in the prevalence of live births among mothers aged 35 years and over. This pattern change poses the need of intensifying maternal mortality surveillance by collecting the necessary set of variables that allow investigation of the causes and determinant factors underlying deaths.

Keys words: Maternal age; Maternal Mortality; Trends; Reproductive Health; Epidemiology. 


\section{INTRODUCTION}

In 2006, with a mean of 1.3 children per woman at reproductive age, Spain ranked among the group of countries with the lowest total fertility rates in the world, only ahead of the Ukraine and Greece (among others) with 1.1 and 1.2 children per woman respectively. In the last twenty years, despite the low fertility, the number of pregnancies among women aged over 35 years has been rising progressively, accounting for $21.2 \%$ of births in 2006.[1] This important increase in fertility among women aged over 35 years has been accompanied by a higher feto-neonatal morbidity and mortality, becoming extremely marked as from age 40 years onwards.[1-3] Similarly, the delay in maternity and the progressive rise in maternal age at date of birth have also resulted in higher female morbidity and mortality. Advanced maternal age has been associated with a higher risk of death $[4,5]$ and an increased risk of delivery by caesarean section during the birth process. $[6,8]$ Maternal mortality is regarded as a preventable cause of death, strongly related to the quality of the healthcare system, and economic and social factors.[9-11] The quality of healthcare and maternal care furnished to pregnant women is an element that may account for the differences between rates.[12, 13] In Spain, a study conducted into the maternal mortality trend for the period 1980-1992 reported a certain stabilisation in the maternal mortality ratio, even so the authors of this study forecast an increase in maternal mortality for the year 2000, associated with advanced maternal age and delay in maternity.[14] Although this increase has also been forecast for France and England for 2005,[15] there are no comparative analysis data available for the prevalence of pregnancies among women aged 35 years and over in Spain versus Europe, and the maternal mortality trend in Spain needs to be re-assessed, as does the impact of advanced age on this trend. Accordingly, this study sought to: compare the prevalence of live births among mothers aged 35 years and over in Spain versus Europe during the last five years of the study period, 2000-2005; analyse the age-related trend in the maternal mortality ratio among mothers in Spain for the decade, 1996-2005; and describe the causes of death and associated socio-demographic factors for the years with highest mortality. 


\section{METHODS}

An ecological study on trends, using aggregate data for the maternal mortality trend during the period 1996-2005; and cross sectional using individual data for describe ascertaining causes of maternal death and associated sociodemographic factors, during 2003-2004.

Data source: Data on Europe were drawn from the European Statistics Office (Eurostat). Eurostat calculates the European aggregates on the basis of the data collected from the National Statistical Offices.[16] Data on Spain were drawn from the National Statistics Institute, we used the movement of natural persons (MNP) and death statistics broken down by cause of death.[17]

Description of variables: The total births by mother's age in Europe, for 2000 to 2005 obtained from Eurostat, were used to describe the prevalence of births among women aged 35 years and over for 15 European Countries. The variables used to describe the maternal mortality trend in Spain were the total number of births and maternal deaths by mother's age at the date of birth for each year of the study period, obtained from the MNP. The definition of maternal mortality used was that proposed by the International Classification of Diseases, 10th Revision (ICD-10), i.e., "the death of a woman while pregnant or within 42 days of termination of pregnancy, irrespective of the duration and site of the pregnancy, from any cause related to or aggravated by the pregnancy or its management, but not from accidental or incidental causes" [18]. The maternal mortality ratio was calculated as the rate between maternal deaths observed for any given year and total live births for this same year expressed per 100,000 newborns; it thus represents the risk of maternal death with respect to the number of newborns. The number of live births used in the denominator is an approximation of the population of pregnant women who are at risk of a maternal death.[19] For the individual description of socio-demographic factors related to maternal deaths, the following variables were used: age; province of birth and death registration; and finally, the ICD-10 diagnostic code of cause of death, obtained from the register of deaths statistics broken down by cause of death. 
Statistical analysis: The median, the interquartile range, and the $5^{\text {th }}$ and $95^{\text {th }}$ percentiles were used for the description of maternal deaths. Considering maternal death as a rare event, and assuming that the maternal mortality ratio follows a Poisson distribution, maternal mortality ratios were calculated together with their respective $95 \%$ confidence intervals.

The trend in observed vis-à-vis expected deaths for each year of study was represented graphically in accordance with a Poisson distribution. The trend in mortality ratios was also represented graphically. A $\chi^{2}$ test for trend was applied to the ratios and, using linear adjustment by the least squares method, a trend line was added to the figure, accompanied by the formula of the equation of the straight line and the coefficient of determination $\left(R^{2}\right)$.

To confirm the trend in the series, standardised mortality ratios were calculated using the indirect method and taking 1996 as reference. Subsequently, in view of the small number of events that occur annually, the mortality ratios of the two quinquennia of the series were calculated in order to give more consistency to the analysis of the series. Using indirect standardisation and taking the five-year period from 1996 to 2000 as reference, the standardised mortality ratio for the five-year period 2001-2005 was then calculated.[20]

To analyse risk of death in terms of maternal age, the age-related mortality rates categorised in three groups ( $\leq 34,35$ to 44 , and $\geq 45$ years) were graphically represented (for the whole study period). A $\chi^{2}$ test for trend was applied to the ratios, and, lastly, a model with an exponential fit was depicted in the figure with its respective equation and coefficient of determination.

An exact Poisson regression was used to estimate the maternal age-related risk of death, adjusted for the study period. The explanatory model used was as follows:

MMR $=\beta_{0}+\beta_{1}{ }^{*}$ Period (continuous variable) $+\beta_{2}{ }^{\star}$ Age (categorical variable)

The statistical test of deviance was used to estimate goodness-of-fit, and an analysis of standardised Pearson residuals was performed. 
Finally, after identifying the years with highest mortality, the socio-demographic factors related to maternal deaths were individually described. The statistical software programme used was Stata v.10 (StataCorp. College Station, TX, USA). 


\section{RESULTS}

The prevalence of live births among women aged 35 years and over in Spain was 15\% higher than the European Union (EU15), over the five-year period 2000-2005. Along with Ireland and Italy, Spain registered the highest prevalence; Portugal was the country with the lowest prevalence (Table1)

Table 1. Prevalence of live births among women aged 35 years and over for 15 European Countries (UE15): 2000-2005.

\begin{tabular}{|c|c|c|c|c|c|}
\hline Countries (EU15) & LBMA $\geq 35$ years $(n)$ & Total Live Births (N) & Prevalence \% (P) & Difference in $\mathbf{P}$ & $\mathbf{P R}^{*}$ \\
\hline Italy & 750,190 & $3,176,749$ & 23.6 & 4.6 & $1.24^{* *}$ \\
\hline Ireland & 83,441 & 355,940 & 23.4 & 4.4 & $1.23^{* *}$ \\
\hline Spain & 566,354 & $2,585,701$ & 21.9 & 2.9 & $1.15^{\star *}$ \\
\hline Sweden & 110,412 & 579,153 & 19.1 & 0.1 & $1.01^{* *}$ \\
\hline Netherlands & 228,506 & $1,193,527$ & 19.1 & 0.1 & $1.01^{* *}$ \\
\hline Luxembourg & 6,103 & 32,616 & 18.7 & {$[-0.3]$} & $0.98^{* *}$ \\
\hline Germany & 797,526 & $4,318,210$ & 18.5 & {$[-0.5]$} & $0.97^{* *}$ \\
\hline Finland & 62,703 & 340,619 & 18.4 & {$[-0.6]$} & $0.97^{* *}$ \\
\hline United Kingdom & 757,974 & $4,150,737$ & 18.3 & {$[-0.7]$} & $0.97^{* *}$ \\
\hline Austria & 72,212 & 404,309 & 17.8 & {$[-1.2]$} & $0.94^{* *}$ \\
\hline France & 786,333 & $4,807,827$ & 16.3 & {$[-2.7]$} & $0.86^{\star *}$ \\
\hline Greece & 101,912 & 626,738 & 16.2 & {$[-2.8]$} & $0.85^{\star *}$ \\
\hline Denmark & 62,301 & 390,264 & 16.0 & {$[-3.0]$} & $0.84^{\star *}$ \\
\hline Portugal & 100,083 & 678,359 & 14.8 & {$[-4.2]$} & $0.78^{* *}$ \\
\hline Belgium $^{* \star *}$ & - & - & - & - & - \\
\hline Total (EU15) (Ref.) & $4,486,050$ & $23,640,749$ & 19.0 & Ref. & Ref. \\
\hline
\end{tabular}

Live Births with maternal age $\geq 35$ years old (LBMA), Reference (Ref.) *Prevalence Ratio ${ }^{* *}$ P-value $<0.01$, ${ }^{* \star *}$ No data

Data Source: Eurostat. In-house.

During the period 1996-2005, there were 148 maternal deaths in Spain. The descriptive analysis revealed an annual median of 15 deaths for the study period, with an interquartile range of 7 , and a $5^{\text {th }}$ and $95^{\text {th }}$ percentile of 8 and 21 deaths respectively. The maternal mortality ratio for the period was $3.6(95 \% \mathrm{Cl}$ : 3.1-4.3) women per 100,000 live births. Taking 1996 as reference, the standardised mortality ratio displayed an upward trend at the limit of significance $(p=0.079)$. Maternal deaths increased by $55 \%$ in the period 2001 2005 compared with 1996-2000 (Table 2). 
Table 2. Maternal Mortality Ratios and Standardized Mortality Ratios in Spain ( $\mathrm{n}: 148$ maternal deaths; $n:$ 4,062,685 live births): 1996-2005.

\begin{tabular}{ccccccc} 
Years/Period & OMD & NLB & $\begin{array}{c}\text { MMR } \\
(\mathbf{9 5} \% \mathbf{C l})\end{array}$ & EMD & SMR & P-value \\
\hline 1996 & 11 & 362,626 & $3.0(1.7-5.5)$ & Ref. & Ref. & $0.079^{*}$ \\
1997 & 8 & 369,035 & $2.2(1.1-4.3)$ & 11 & $0.7(0.5-1.1)$ & $0.9(0.6-1.3)$ \\
1998 & 10 & 365,193 & $2.7(1.5-5.1)$ & 11 & $1.3(0.9-1.7)$ \\
1999 & 15 & 380,130 & $4.0(2.4-6.5)$ & 11 & $1.2(0.9-1.6)$ \\
2000 & 14 & 397,632 & $3.5(2.1-5.9)$ & 12 & $1.4(0.9-1.8)$ \\
2001 & 17 & 406,380 & $4.2(2.6-6.7)$ & 12 & $1.1(0.8-1.5)$ \\
2002 & 14 & 418,846 & $3.3(2.0-5.6)$ & 13 & $1.5(1.2-1.9)$ \\
2003 & 20 & 441,881 & $4.5(2.9-7.0)$ & 13 & $1.5(1.2-2.0)$ \\
2004 & 21 & 454,591 & $4.6(3.0-7.1)$ & 14 & $1.3(0.9-1.7)$ \\
2005 & 18 & 466,371 & $3.9(2.4-6.1)$ & 14 & Ref. & $0.089^{* *}$ \\
\hline 1996 to 2000 & 58 & $1,874,616$ & $3.1(2.4-4.0)$ & Ref. & $1.2(0.9-1.4)$ \\
\hline
\end{tabular}

Observed Maternal deaths (OMD), Number of live births (NLB), Maternal Mortality Ratio (MMR), Expected Maternal Death (EMD), , Standardised Mortality Ratio (SMR).

* Trend $\chi^{2}{ }^{* *} \chi^{2}$ for unequal rates

Data source: INE, In-house

The maternal mortality ratio for the study period reflected linear growth $(p=$ 0.012) (Figure 1) and indicated two years with highest mortality. The maternal mortality represented a 50\% increase mortality in 2003 and 2004, taking as reference 1996 (Table 2).

Across the entire study period, the curve that best explained the trend in maternal age-related mortality ratios was that which depicted exponential growth (Figure 2).

Adjusted for the study period, the maternal age group ranging from 35 to 44 years displayed a 2.9-fold higher risk of death compared to the 34-and-under age group. This higher risk rose to as much as 89.2 -fold in the case of the 45and-over age group (Table 3). 
Table 3. Maternal mortality ratios according to maternal age and study period ( $\mathrm{n}$ : 148 maternal deaths): 1996-2005.

\begin{tabular}{rccc} 
& Coefficient (Standard Error) & RR $(\mathbf{9 5 \%} \text { Cl) })^{\mathbf{a}}$ & P-value \\
\hline Period: 1996 -2005 & $0.04(0.03)$ & $1.04(0.98-1.10)$ & 0.181 \\
Maternal Age: & & & $<0.001$ \\
35 to 44 vs. $\leq$ 34 & $1.05(0.18)$ & $2.90(2.01-4.06)$ & \\
$\geq$ 45 vs. $\leq$ 34 & $4.50(0.42)$ & $89.2(39.04-203.85)$ & \\
\hline
\end{tabular}

${ }^{a}$ Relative Risk. Goodness-of-fit $\chi^{2}: 26.7, p=0.421$

Age-related socio-demographic characteristics, nationality (Spanish versus foreign), province of death, and cause of death in respect of the 41 mothers who died in the two years that registered highest mortality (2003-2004) are summarised in Table 4 . It should be stressed here that $32 \%$ of deaths were of foreign origin, $57 \%$ were aged 35 years and over, $20 \%$ of deaths occurred in only one province (Málaga). The mortality risk in Málaga, taking the maternal mortality ratio of others provinces as reference was 6 times higher (Rate Ratio 6.4 95\% $\mathrm{Cl}: 2.6-14.2$ ), and the mortality risk of death from foreign mothers, taking nationals mothers as reference was 3.1 times higher (Rate Ratio 3.1 95\% Cl: [1.5-6.1]). The number of maternal deaths by provinces in Spain for the period 2003-2004 were: Alicante (3), Almeria (1), Asturias (3), Badajoz (1), Balearic Isles (1), Barcelona (5), Cadiz (1), Ceuta (1), Jaén (2), Las Palmas (1), Lleida (1), Madrid (5), Málaga (8), Murcia (1), Santa Cruz de Tenerife (2), Seville (1), Pontevedra (1), Valladolid (1), Zaragoza (1) (Figure 3). The groups 010-016 and 085-092 are presenting a 48.7\% of all deaths of the biennium 2003, 2004. In the first group, pre-eclampsia/eclampsia accounts for $90 \%$ (9 deaths) of the deaths and embolism (amniotic fluid, 4 deaths, the blood clot in obstetrics, 3 deaths and other obstetric embolism, 1 death) accounts for $80 \%$ of deaths in the second group. 
Table 4. Maternal Mortality Ratios, socio-demographic characteristics and causes of death as per ICD-10 in Spain ( $\mathrm{n}: 41$ maternal deaths; $n:$ 896,472 live births): 2003-2004.

\begin{tabular}{|c|c|c|c|c|}
\hline Variables & & $\mathbf{N}(\%)$ & TLB (n) & $\begin{array}{c}\text { MMR } \\
(95 \% \mathrm{Cl})\end{array}$ \\
\hline \multicolumn{5}{|l|}{ Province of death } \\
\hline & Málaga & $8(19.5)$ & 32,450 & $24.6(10.6-48.6)$ \\
\hline & Others* & $33(80.5)$ & 864,022 & $3.8(2.6-5.3)$ \\
\hline \multicolumn{5}{|l|}{ Age in years } \\
\hline & $\leq 34$ & $18(43.9)$ & 746,771 & $2.4(1.4-3.8)$ \\
\hline & 35 to 44 & $21(51.2)$ & 149,049 & $14.1(0.9-21.5)$ \\
\hline & $\geq 45$ & $2(4.9)$ & 652 & $306.7(34.4-1170.0)$ \\
\hline \multicolumn{5}{|l|}{ Nationality } \\
\hline & $\begin{array}{l}\text { Foreign } \\
\text { nationals }\end{array}$ & $13(31.7)$ & 116,661 & $10.1(0.6-1.9)$ \\
\hline & $\begin{array}{l}\text { Spanish } \\
\text { nationals }\end{array}$ & $28(68.3)$ & 779,811 & $3.6(2.4-5.2)$ \\
\hline \multicolumn{5}{|l|}{ ICD-10 cause } \\
\hline Pregnancy with abortive outcome. & O00-O08 & $4(9.7)$ & 896,472 & $0.4(0.1-1.1)$ \\
\hline \multirow{2}{*}{$\begin{array}{l}\text { Oedema, proteinuria and hypertensive disorders } \\
\text { in pregnancy, childbirth and the puerperium. } \\
\text { Maternal care related to the foetus and amniotic } \\
\text { cavity and possible delivery problems. }\end{array}$} & O10-O16 & $10(24.4)$ & 896,472 & $1.1(0.5-2.0)$ \\
\hline & O30-O48 & $5(12.2)$ & 896,472 & $0.5(0.2-1.3)$ \\
\hline \multirow{2}{*}{$\begin{array}{r}\text { Complications of labour and delivery. } \\
\text { Complications predominantly related to the } \\
\text { puerperium. }\end{array}$} & O60-O75 & $7(17.1)$ & 896,472 & $0.7(0.3-1.6)$ \\
\hline & O85-092 & $10(24.4)$ & 896,472 & $1.1(0.5-2.0)$ \\
\hline $\begin{array}{r}\text { Other obstetric conditions, not elsewhere } \\
\text { classified. }\end{array}$ & O95-O99 & $5(12.2)$ & 896,472 & $0.5(0.2-1.3)$ \\
\hline
\end{tabular}

Total Live Births (TLB) * Others provinces deaths: Alicante, Almeria, Asturias, Badajoz, Balearic Isles, Barcelona, Cadiz, Ceuta, Jaén, Las Palmas, Lleida, Madrid, Murcia, Santa Cruz de Tenerife, Seville, Pontevedra, Valladolid, Zaragoza.

Data source: INE, in-house. 


\section{CONCLUSIONS:}

From 1930 up to the 1980s, the maternal mortality ratio registered a clear decline in most European countries, with it then remaining stable in the following years.[21, 22] In the 1990s, different authors forecast a rise in the maternal mortality ratio by the beginning of the $21^{\text {st }}$ century, specifically in Spain, France and the United Kingdom.[14, 15] In line with these forecasts, the results of this study confirm a change in the maternal mortality trend in Spain over the decade 1996-2005.

In Spain, the risk of maternal mortality grew exponentially with mothers' age over the decade 1996-2005. This is the first time that a study has drawn attention to the high percentage of maternal deaths among the foreign population in Spain (32\% of total deaths during the two-year period from 2003 to 2004). In this respect, other studies have identified women at advanced reproductive age and immigrants from developing countries as risk groups for maternal mortality.[13, 15] However, the data yielded by our study do not enable us to specify what percentage of the figure of $32 \%$ recorded for deaths among foreign mothers is attributable to mothers from developing countries. In this connection, a study on maternal mortality in Europe highlights the fact that there is a wide disparity between migrants from developing countries and the native population in terms of access to health. Communication problems between health professionals and immigrant patients have been postulated as being a key factor underlying this problem.[23]

According to Eurostat data, the mean age of first pregnancy in most European countries is rising.[16] The determinants of this process can be explained by the social, economic and cultural changes that took place in western societies in the last third of the $20^{\text {th }}$ century. Specifically, here in Spain, the lack of conciliation between professional and family life, absence during years of maternity of protective policies, and the progressive medicalisation of pregnancy and birth have been suggested as determinants of the increase in the mean age of mothers at first pregnancy.[24] Furthermore, the development of assisted reproduction techniques, different prenatal diagnostic tests, legal termination of pregnancy after prenatal diagnosis of congenital defects,[25] and delivery by 
caesarean section with enhanced safety for mother and foetus, have brought greater guarantees of safety for couples who can now delay maternity with a certain degree of tranquillity.[26]

This would account for the fact that Spain and Italy, with some of the lowest total fertility rates in Europe (a mean of 1.2 to 1.3 children per woman at reproductive age),[16] are the two countries which have the highest number of assisted reproduction clinics (115 and 182 respectively) and register the highest prevalence of births among women aged 35 years and over in Europe.[27] This change in the fertility pattern has led some authors to forecast future rises in maternal mortality.[15, 22]

The individual descriptive analysis of maternal deaths which occurred during the two-year period with highest mortality (2003-2004), has enabled a cluster of deaths to be located in one Spanish province. Confidential surveys conducted in France, United Kingdom and Holland in the 1990s estimated that the proportion of maternal deaths which did not benefit from an optimal level of care accounted for $50 \%$ to $80 \%$ of the cases reviewed.[28-30] Accordingly, this is a factor that might well explain the difference in maternal mortality between regions.

This is why confidential investigations into maternal death are indispensable for furnishing a more reliable image of what is in fact happening. Such research requires every effort to be made to gather comprehensive data on all the possible variables underlying the event. Individualised nation-wide studies on maternal deaths started being conducted in the United Kingdom in 1952 and in The Netherlands shortly thereafter.[13, 31]

Insofar as the limitations of this study are concerned, it must be stressed that, when one talks of risk of maternal mortality associated with age, this is not interpretable at an individual level: to do so, would be to fall foul of an ecological fallacy. Different authors have highlighted problems of under-registration and under-reporting of maternal deaths in different European countries and Spain,[32] and so the results of our study could be underestimated. One must be prudent when it comes to interpreting the results, in view of the fact that probability distributions for infrequent events increase the risk of type I error 
and, at times, yield p-values that are difficult to interpret. To solve this problem when analysing the data, we therefore endeavoured to lend the results greater consistency by adding maternal deaths for periods of five years in order to perform five-yearly comparisons. Prudence is also called for when it comes to interpreting the mortality cluster detected. For a correct interpretation, one would have to access to a longer time series. Similarly, it is highly likely that most of the clusters of adverse results in reproductive health are random events: only a very small proportion are caused by environmental agents, which could be identified by exhaustive epidemiological research.[33, 34]

The change in the maternal mortality pattern detected marked by a rising trend and an increased risk at advanced maternal ages, the detection of a cluster with geographical excess mortality, plus the high prevalence of pregnancies among women aged 35 years and over in Spain versus other European countries, justify the need for more intense and detailed epidemiological surveillance of a preventable phenomenon. It would be desirable to conduct an assessment of under-registration and under-reporting, implement active surveillance to put a halt to geographical clusters, use qualitative surveys for analysis of the socioeconomic and health-care circumstances surrounding deaths, and perform comparative quantitative analyses in the European sphere, both national and regional. These measures would be invaluable for in-depth understanding and characterisation of a preventable phenomenon such as maternal death.

What is already known on this subject?

The delay in maternity and the progressive rise in maternal age at date of birth have also resulted in higher female morbidity and mortality. Maternal mortality is regarded as a preventable cause of death, strongly related to the quality of the healthcare system, and economic and social factors.

Different studies forecast an increase in maternal mortality, associated with advanced maternal age and delay in maternity in the next years. The maternal mortality trend in Spain needs to be re-assessed, as does the impact of advanced age on this trend. 


\section{What does this study add?}

This study adds a change in the maternal mortality pattern in Spain marked by a rising trend and an increased risk at advanced maternal ages, the detection of a cluster with geographical excess mortality, plus the high prevalence of pregnancies among women aged 35 years and over in Spain versus other European countries.

This pattern change poses the need of intensifying maternal mortality surveillance in Spain by collecting the necessary set of variables that allow investigation of the causes and determinant factors underlying deaths. Implement active surveillance to put a halt to geographical clusters, use qualitative surveys for analysis of the socio-economic and health-care circumstances surrounding deaths, and perform comparative quantitative analyses in the European sphere, both national and regional. These measures would be invaluable for in-depth understanding and characterisation of a preventable phenomenon such as maternal death.

\section{Competing interests: None.}

Funding: None.

Contributors: MALF designed the study. All authors analysed and interpreted the data. MALF wrote the manuscript. All authors conducted background literature reviews and edited the paper.

Statement: "The Corresponding Author has the right to grant on behalf of all authors and does grant on behalf of all authors, an exclusive licence (or non exclusive for government employees) on a worldwide basis to the BMJ Publishing Group Ltd to permit this article (if accepted) to be published in JECH and any other BMJPGL products and sublicences such use and exploit all subsidiary rights, as set out in our licence (http://jmg.bmj.com/ifora/licence.pdf)." 


\section{REFERENCES}

1. Luque Fernández MA. [Trends in the risk of late fetal mortality, prematurity and low birth weight associated with advanced maternal age in Spain [1996-2005].] Gac Sanit.

2008;22(5):396-403

2. Nabukera S, Wingate MS, Alexander GR, Salihu HM. First-time births among women 30 years and older in the United States: patterns and risk of adverse outcomes. J Reprod Med. 2006;51(9):676-82.

3. Jacobsson B, Ladfors L, Milsom I. Advanced maternal age and adverse perinatal outcome. Obstet Gynecol. 2004;104(4):727-33.

4. Seoud MA, Nassar AH, Usta IM, Melhem Z, Kazma A, Khalil AM. Impact of advanced maternal age on pregnancy outcome. Am J Perinatol. 2002;19(1):1-8

5. Diejomaoh MF, Al-Shamali IA, Al-Kandari, Al-Qenae M, Mohd AT. The reproductive performance of women at 40 years and over. Eur J Obstet Gynecol Reprod Biol. 2006; 126(1):33-8

6. Martínez-Frías ML, Bermejo E, Rodríguez-Pinilla E, Dequino G. Evolución secular y por autonomías de la frecuencia de tratamientos de fertilidad, partos múltiples y cesáreas en España. Med Clin (Barc). 2005;124(4):132-9

7. Ecker JL, Chen KT, Cohen AP, Riley LE, Lieberman ES. Increased risk of cesarean delivery with advancing maternal age: indications and associated factors in nulliparous women. Am J Obstet Gynecol. 2001;185(4):883-7

8. Heffner LJ, Elkin E, Fretts RC. Impact of labor induction, gestational age, and maternal age on cesarean delivery rates. Obstet Gynecol. 2003;102(2):287-93

9. Bouvier-Colle $\mathrm{MH}$, Pequignot $\mathrm{F}$, Jougla $\mathrm{E}$. Mise au point sur la mortalité maternelle en France: fréquence, tendances et causes. J Gynecol Obstet Biol Reprod (Paris). 2001;30(8):768-75

10. Sheiner E, Shoham-Vardi I, Hershkovitz R, Katz M, Mazor M. Infertility treatment is an independent risk factor for cesarean section among nulliparous women aged 40 and above. Am J Obstet Gynecol. 2001;185(4):888-92.

11. Bouvier-Colle MH, Varnoux N, Bréart G. Les morts maternelles en France. INSERM, Paris 1994. 
12. UK Health Department. Report on Confidential Enquiries into maternal deaths in the United Kingdom 1991-1993. London, HMSO, 1994.

13. Schuitemaker N, van Roosmalen J, Dekker G, van Dongen P, van Geijn H, Bennebroek Gravenhorst J. Confidential enquiry into maternal deaths in The Netherlands 19831992. Eur J Obstet Gynecol Reprod Biol. 1998;79(1):57-62

14. Valero LF, Saénz MC. [Maternal mortality in Spain, 1980-1992. Relationship with birth distributions according to the mother's age]. Rev Clin Esp. 1997;197(11):764-7

15. Salanave B, Bouvier-Colle $\mathrm{MH}$. The likely increase in maternal mortality rates in the United Kingdom and in France until 2005. Paediatr Perinat Epidemiol. 1996;10(4):41822.

16. EUROSTAT [Database] Statistical Office of the European Communities. http://epp.eurostat.ec.europa.eu/ (accessed 8 July 2008)

17. INE [Database]. España: Instituto Nacional de Estadística; 1975-. www.ine.es/inebase/ (accessed 8 July 2008)

18. WHO. International Classification of Diseases. $10^{\text {th }}$ Revision. Geneva, World Health Organization, 2004.

19. WHO. Maternal mortality in 2005. Estimates developed by WHO, UNICEF and UNFPA. Geneva. World Health Organisation. 2007.

20. Eastern Region Public Health Obervatory. INphoRM 6:Standardisation. Erpho 2005;6. www.erpho.org.uk/Download/Public/12267/1/INPHORM\%206\%20FINAL.pdf (accesed 4 December 2008)

21. Schuitemaker NW, Gravenhorst JB, Van Geijn HP, Dekker GA, Van Dongen PW. Maternal mortality and its prevention. Eur J Obstet Gynecol Reprod Biol. 1991;42 (Supl):S31-5.

22. Atrash HK, Alexander S, Berg CJ. Maternal mortality in developed countries: not just a concern of the past. Obstet Gynecol. 1995;86:700-5.

23. Schuitemaker NW. Maternal mortality in Europe; present and future. Eur J Obstet Gynecol Reprod Biol. 1999;86(2):129-30 
24. Maroto-Navarro G, del Mar Garcia-Calvente M, Mateo-Rodriguez I. The challenge of maternity in Spain: social and health difficulties. Gac sanit. 2004;18(2):13-23.

25. Martínez-Frías ML, Bermejo E. Frecuencia basal de defectos congénitos en España y su evolución en el tiempo: utilidad y significado de las distintas cifras de frecuencia. Med Clin (Barc). 1999;113(12):459-62.

26. Sachs BP, Castro MA, Frigoletto F. The risk of lowering the cesarean-delivery rate. $N$ Engl J Med. 1999;340:54-7.

27. Andersen AN, Gianaroli L, Felberbaum R, de Mouzon J, Nygren KG. Assisted reproductive technology in Europe, 2001. Results generated from European registers by ESHRE. Hum Reprod. 2005;20(5):1158-76.

28. Bouvier-Colle MH, Varnoux N, Bréart G.Maternal deaths and substandard care: the results of a confidential survey in France. Medical Experts Committee. Eur $J$ Obstet Gynecol Reprod Biol. 1995;58(1):3-7.

29. Benbow A, Maresh M. Reducing maternal mortality: reaudit of recommendations in reports of confidential inquiries into maternal deaths. BMJ. 1998;317(7170):1431-2.

30. Wildman K, Bouvier-Colle MH; MOMS Group. Maternal mortality as an indicator of obstetric care in Europe. BJOG. 2004;111(2):164-9.

31. UK Health Department. Report on Confidential Enquiries into Maternal Deaths in the United Kingdom 1994-1996. London: HMSO, 1998.

32. de Miguel Sesmero JR, Temprano González MR, Muñoz Cacho P, Cararach Ramoneda V, Martínez Pérez Mendaña J, Mínguez JA, et al. Mortalidad materna en España en el período 1995-1997: resultados de una encuesta hospitalaria. Prog Obst Ginecol. 2002;45(12):525-34

33. Guidelines for investigating clusters of health events. MMWR Recomm Rep. 1990;39(RR-11):1-23.

34. Niyonsenga T, De Wals P. A method for the follow-up of clusters of adverse reproductive outcomes. Eur J Epidemiol. 1999;15(9):833-7. 


\section{Figures legend:}

Figure 1.

Annual trend in the absolute number of deaths and maternal mortality ratios for the period 1996-2005 (n: 148).

Figure 2.

Age-related maternal mortality ratio for the period 1996-2005 ( $n: 148)$.

Figure 3.

Maternal Mortality by province of death in Spain (n: 41): 2003-2004. 


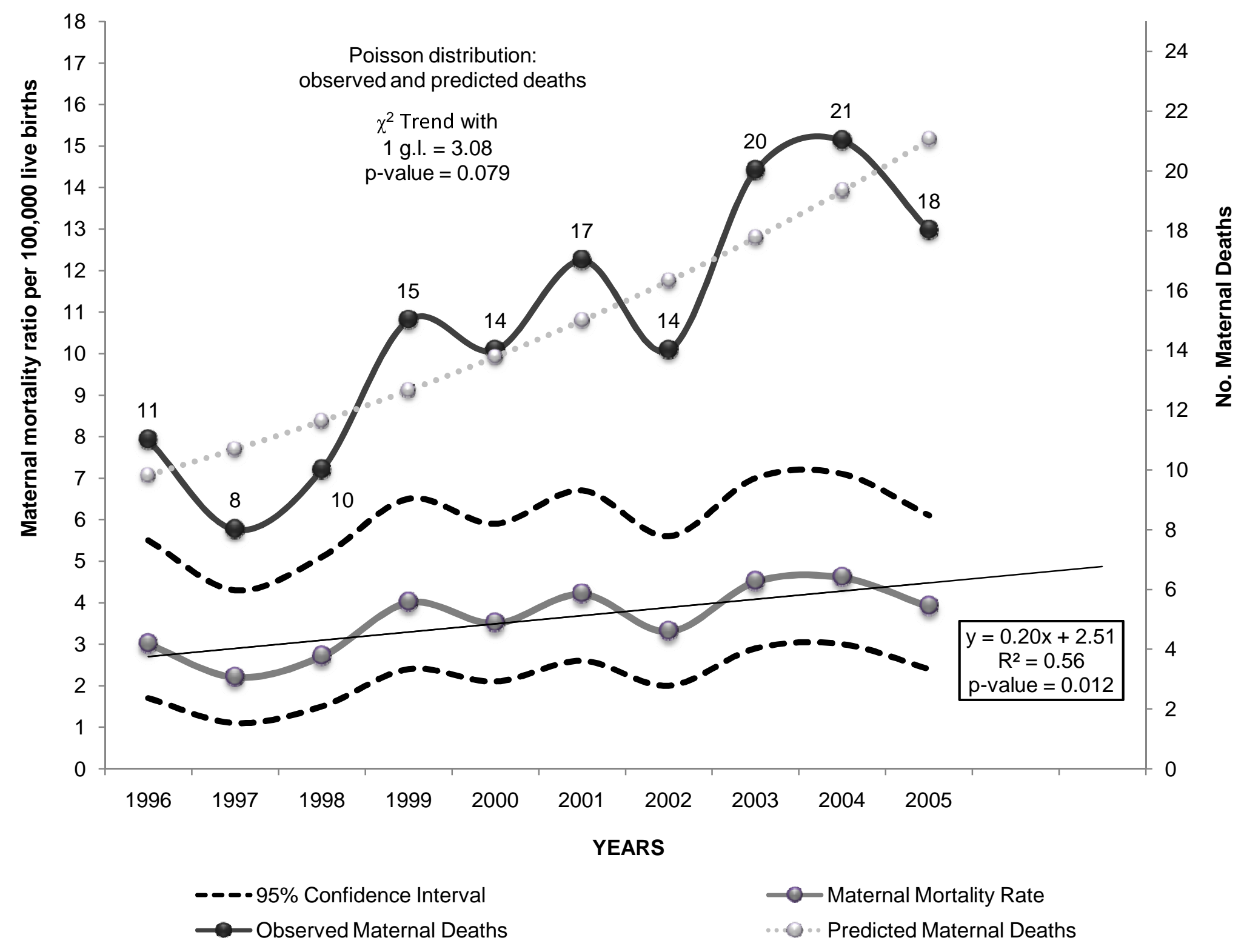

Data source: National Statistics Institute (Instituto Nacional de Estadística - INE). In-house 


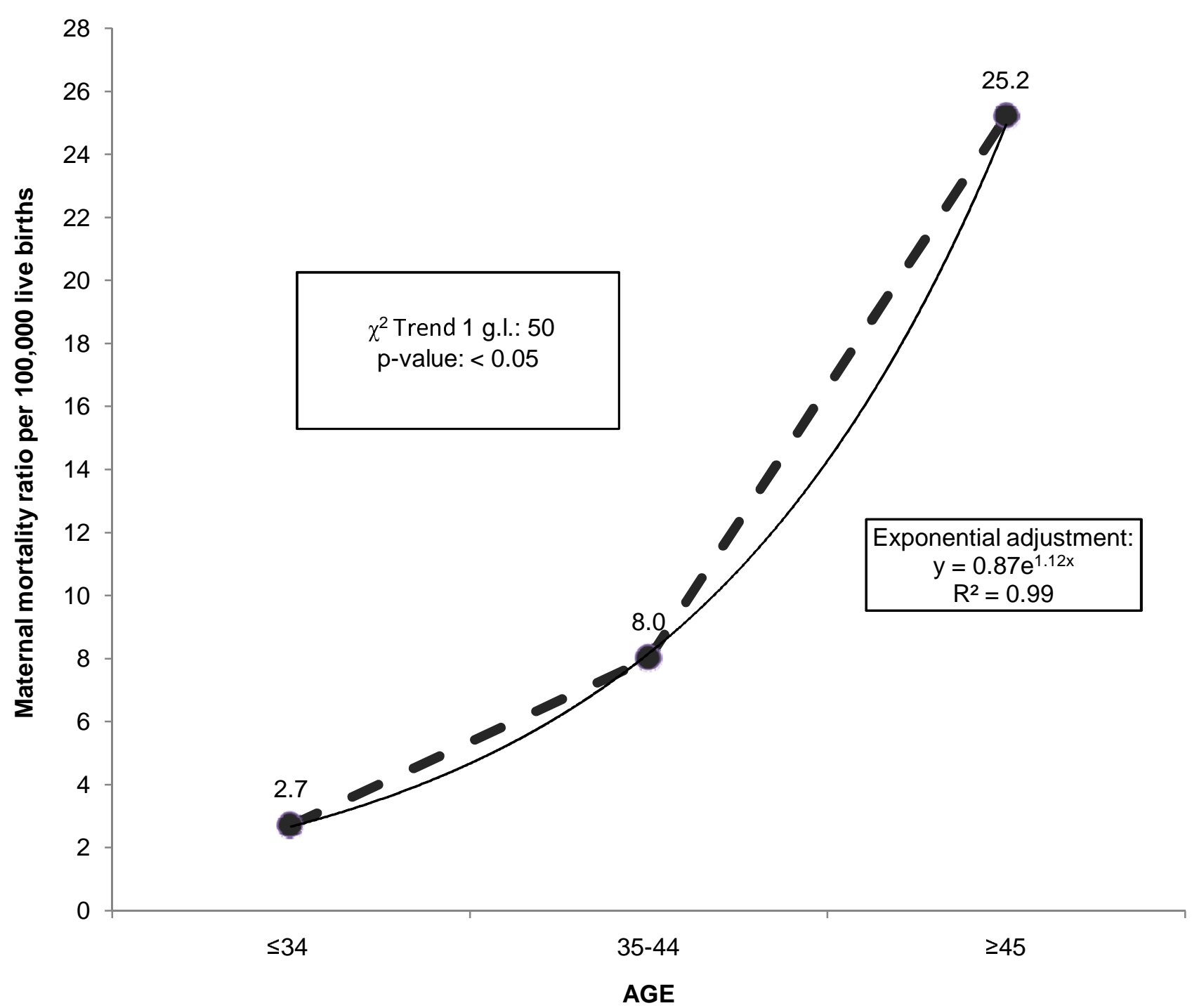

Data source: National Statistics Institute (Instituto Nacional de Estadística - INE). In-house 


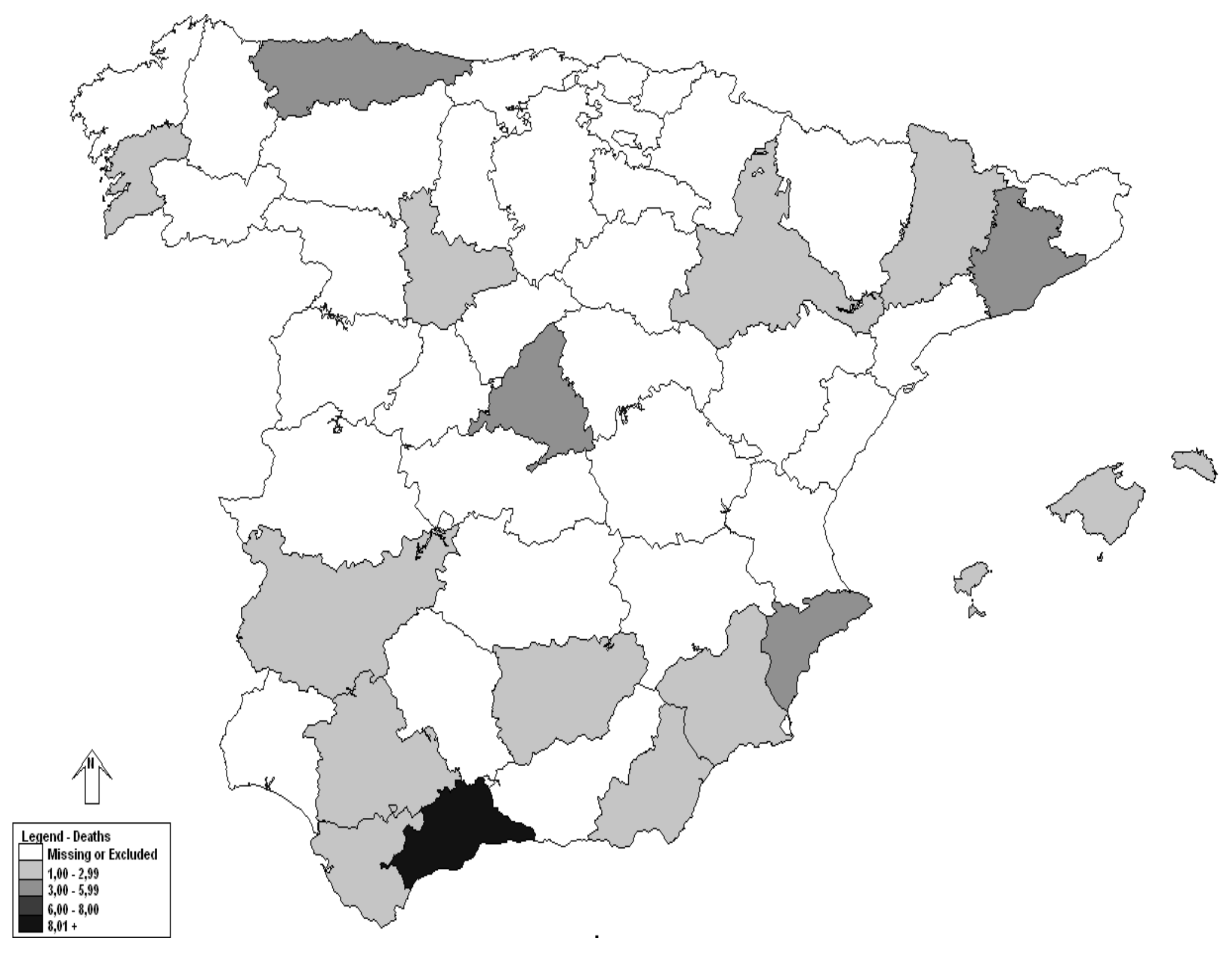

Data source: INE, in-house 
